\title{
Design of an Automatic Tester for Armored Vehicle Weapon System Cable
}

\author{
Hejia Li \\ Changchun Institute of Engineering Technology \\ Control Engineering Department \\ Changchun, China \\ e-mail:275039646@qq.com
}

\section{Cheng Yao}

Changchun Institute of Engineering Technology

Control Engineering Department

Changchun, China

e-mail:250849643@qq.com

\section{Zhao Yao}

Changchun Institute of Engineering Technology

Control Engineering Department

Changchun, China

e-mail:22162338@qq.com

\section{Guohua Zang}

Changchun Institute of Engineering Technology

Control Engineering Department

Changchun, China

e-mail:275039656@qq.com

\author{
Xilong Chen \\ Changchun Institute of Engineering Technology \\ Training Department \\ Changchun, China \\ e-mail:53041915@qq.com
}

\section{Jiuchao Li}

Changchun Institute of Engineering Technology Control Engineering Department

Changchun, China

e-mail:275039665@qq.com

\section{Yongqiang Hou}

Changchun Institute of Engineering Technology Control Engineering Department

Changchun, China e-mail:272456116@qq.com

\author{
Hui Jiang \\ Changchun Institute of Engineering Technology \\ Control Engineering Department \\ Changchun, China \\ e-mail:375049746@qq.com
}

\begin{abstract}
Aimed at the armored vehicle weapon system cables' characteristics and the requirements of their parameter-testing, a kind of tester which realizes the automatic detection of the cables is designed. The tester is based on the principle of voltage comparion, which is controlled by an embedded controller and uses the method of relay matrix to achieve the automatic choosing and turnon of the signals for the detection of cable. According to the cable's connection mode, it can test both the cable's connection resistance and the insulation resistance, so it will realize the intelligent and high-speed automatic detection and testing. Because of the use of high-voltage stable power supply, the optimization design of the hardware and other measurements, the noises during the progress of the test are reduced, the methods of Gray Theory and Least Square Method are discussed to reduce the measurement errors, so as to improve the testing precision of the resistance.
\end{abstract}

Keywords-Vehicle Weapon System Cable; relay Matrix; Insu Lation Resistance Connection Mode; Embedded Controller; USB Communications.

\section{INTRODUCTION}

Among the armored vehicle weapon systems, cable occupies an important position, because the transmission of various signal and command is inseparable from the cable, its reliability is related to the security and stability of the weapon system, and insulation resistance value. The resistance value is an important performance index of cable, therefore researchers need to test the insulation mode and conduction mode of cable before the operation of the weapon system, ensure that the value of insulation resistance and resistance value is normal. At present, for some type of armored vehicle weapon system cable, the periodic artificial method in the test of insulation resistance value and the resistance value is mainly adopted. By using the combined method of multimeter and megohmmeters, this paper tests the cable network one by one and point by point This test method has much accidental factors, workload, slow test speed, long detection time, and it is prone to misuse and make wrong judgment, prone to data recording errors, thereby affecting the reliability of data processing and test results, affects the rapid mobility of armored forces and shortens the launching time. Therefore, the intelligent detection and control technology of single-chip microcomputer are adopted as the core to carry out development of cable automatic test instrument, and achieve automatic test of cable conduction mode and insulation mode[1], so as to improve the performance of weapon detection speed, repair safeguard and force reaction force.

\section{SYSTEM TESTING PRINCIPLE}

The principle of the tester for cable conduction resistance and insulation resistance value is the same[2], in 
the use of voltage comparison method, as shown in Fig. 1 and Fig. 2.

For the test circuit of the resistance value, $R_{1} 、 R_{2}$ are known resistance value, $R_{3}$ is known variable resistance, $R_{X}$ is the cable core wire insulation resistance value, $R_{2}$ voltage can be calculated, $U_{1}=15 \times R_{2} / R_{1}+R_{2}, R_{X}$ voltage is $U_{2}$, through calculate $U_{1}-U_{2}$ to get $U_{2}$, calculate
$U_{2}=15 \times R_{X} / R_{3}+R_{X}$ to get $R_{X}, R_{X}=U_{2} R_{3} / 15-U_{2}$, the test method of insulation resistance and resistance value is similar, but also provides a reference voltage by the operational amplifier, calculate $R_{1}$ voltage by the operational amplifier, using the divider

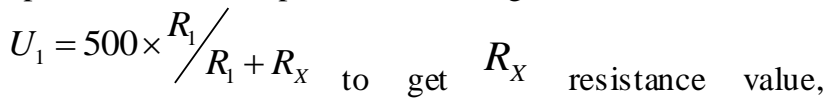
$R_{X}=500-U_{1} / U_{1} R_{1}$

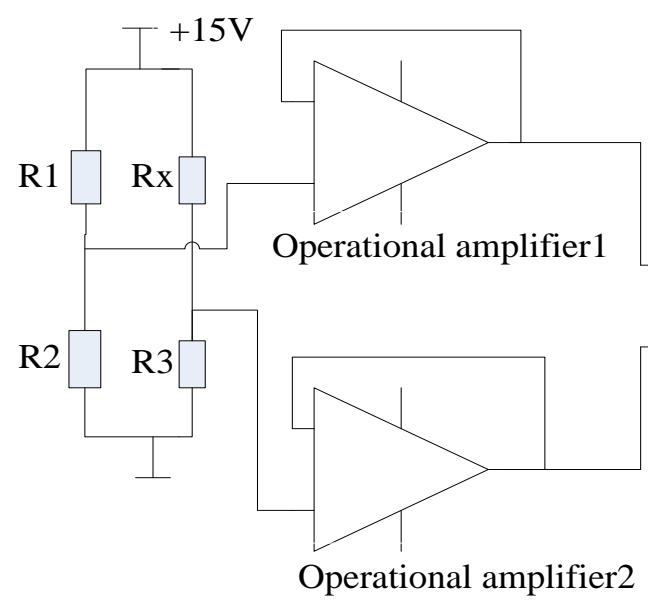

$\mathrm{A} / \mathrm{D}$

Converter

Differential amplifier

Figure 1. Conduction resistance test circuit

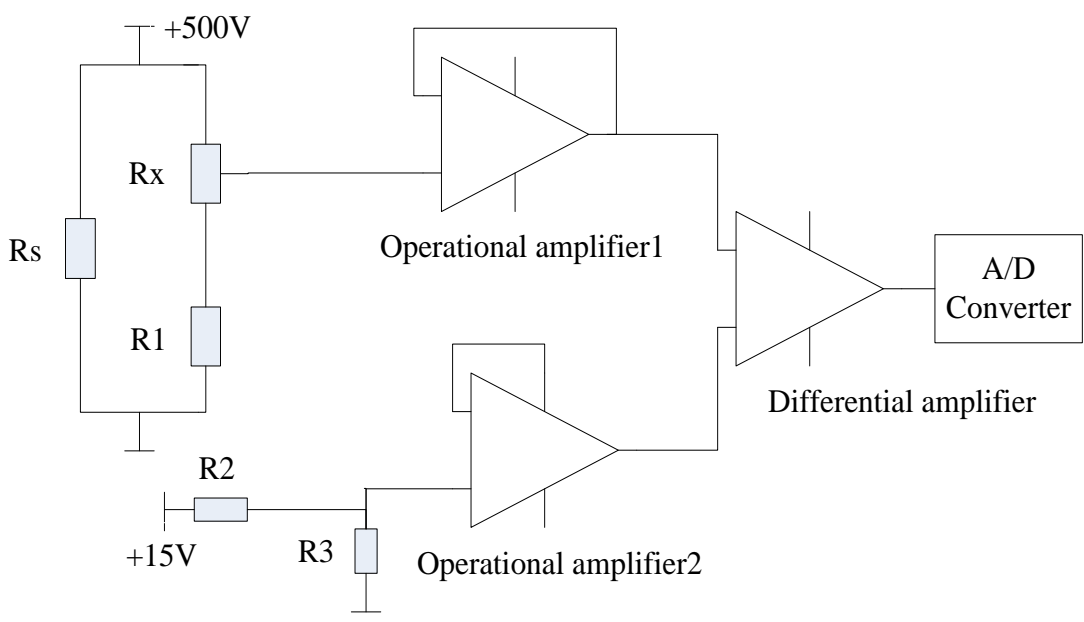

Figure 2. Insulation resistance test circuit

\section{SYSTEM HARDWARE DESIGN}

Tester hardware is mainly composed of a power supply, SCM[4], relay matrix, conduction and insulation resistance testing and sampling, LCD display, printer and USB communication interface and other components, as shown in Fig. 3.

SCM is the core of the instrument, through which to achieve intelligent instrument, it can control the power supply automatic range switching, Automatic selection can be controlled, so as to realize the relay matrix of cable cores, can also be used to process and store the data converted by the A/D.

The power part can switch $+26 \mathrm{~V}$ into various voltage required for system, low voltage source module is to s witch $+26 \mathrm{~V}$ into $+5 \mathrm{~V},+12 \mathrm{~V},+15 \mathrm{~V}$ required for the MCU. High voltage power supply module is to switch $+26 \mathrm{~V}$ into $+100 \mathrm{~V},+500 \mathrm{~V},+1000 \mathrm{~V}$ for the insulation resistance test, 3-gear selection is to be achieved by the automatic range switching circuit. Among them, the high voltage power is controlled by PWM switching power supply module driver, with the advantages of small volume, small ripple, high 
energy conversion efficiency, high stability, less susceptible to interference and better precision.

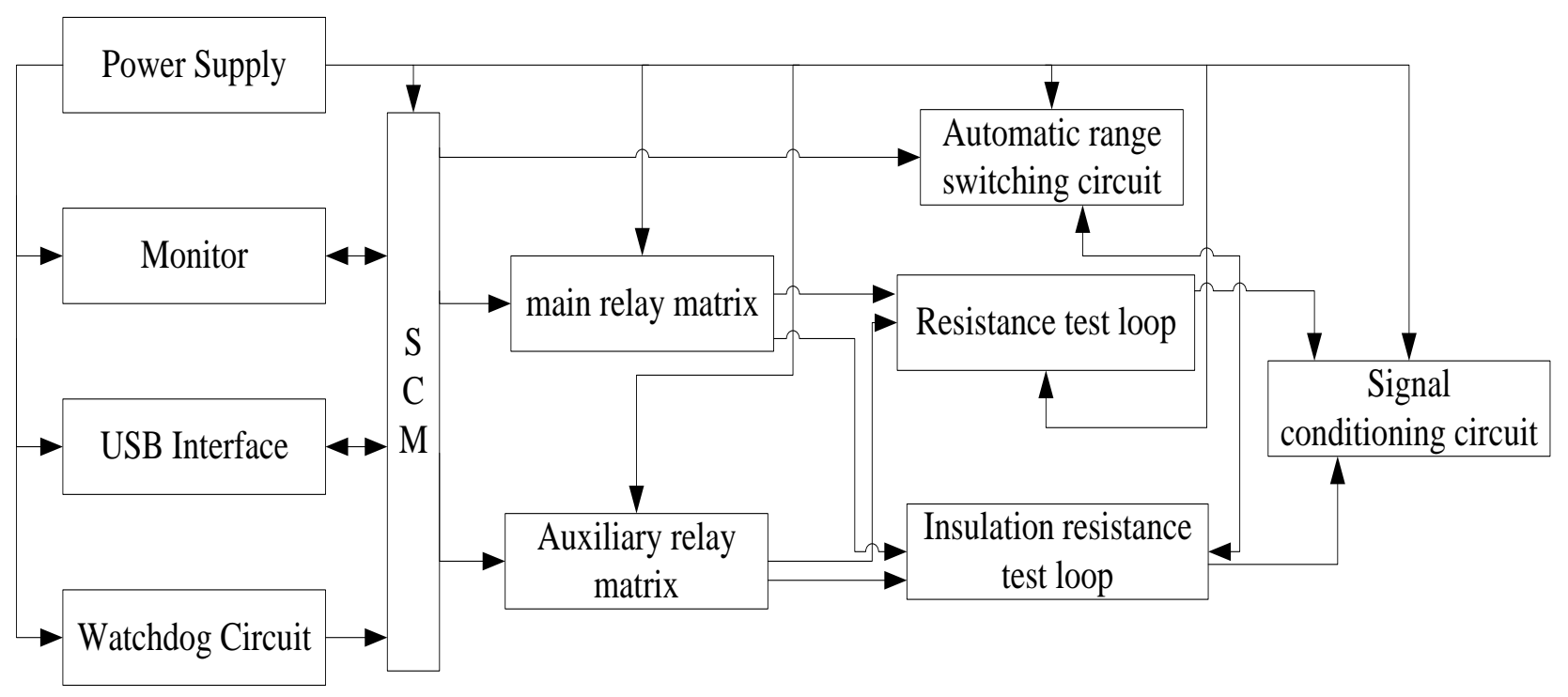

Figure 3. System structure diagram

According to the output signal of resistance testing circuit and insulation resistance test circuit, the signal conditioning circuit is to complete signal filtering, isolation, amplification, A/D conversion into the SCM, according to test requirements, SCM open channel read data and complete the signal acquisition [5].

The internal core wire selection mainly adopts relay matrix to achieve[6], through the control of the corresponding relay pull and turn off, achieve the core wire interface connect and disconnect[7].

\section{SYSTEM SOFTWARE DESIGN}

The test software is written by the object-oriented language $\mathrm{C}++$ with the versatility, which can be easily ported to the conduction and insulation resistance test of other types of armored vehicle weapon system cable. The development of automatic test software is mainly from the following aspects: the arrangement of the test system interface, the process control of the test process: the test data management. The core of the testing software is the test of the conduction resistance and insulation resistance, the test includes two ways, namely the automatic strobe all cable and the manual specified core wire, the testing process is shown in Fig. 4.

The user first needs to determine the measurement mode, namely test on resistance or insulation resistance. On the basis of the choice of core test mode, if you choose the manual, you will need to enter the test core wire number, after entering the system, first determine whether the core wire is effective, and then the test voltage inputs the circuit. If you select automatic gear, when test the insulation resistance, because the voltage source has 3 stalls/ If the initial voltage is too low, realize the transformation by automatic range switching circuit through the feedback, the system will test, return and record test data of each point, until the end of the test. When conducting resistance test, because the test voltage is $+15 \mathrm{~V}$, it can directly test.

According to the test requirements, automatic test interface is divided into 3 zones, Zone 1 is the basic information, including product "batch", "number", "date" and "test items, Zone 2 is automatic detection results display area, show the specific test numerical parameters, Zone 3 is the result of evaluation, the test values of each parameter and the requirements "cable manufacture and acceptance specification" are compared, judge whether the results are qualified or unqualified, and the results are shown in " test result" [8].

Data management is used to manage test results, including data storage, browsing, query and other functions. Etablish the fault database, carry on the preliminary analysis on the fault location in the testing process, to maintain it regularly update, etc.[9]. 


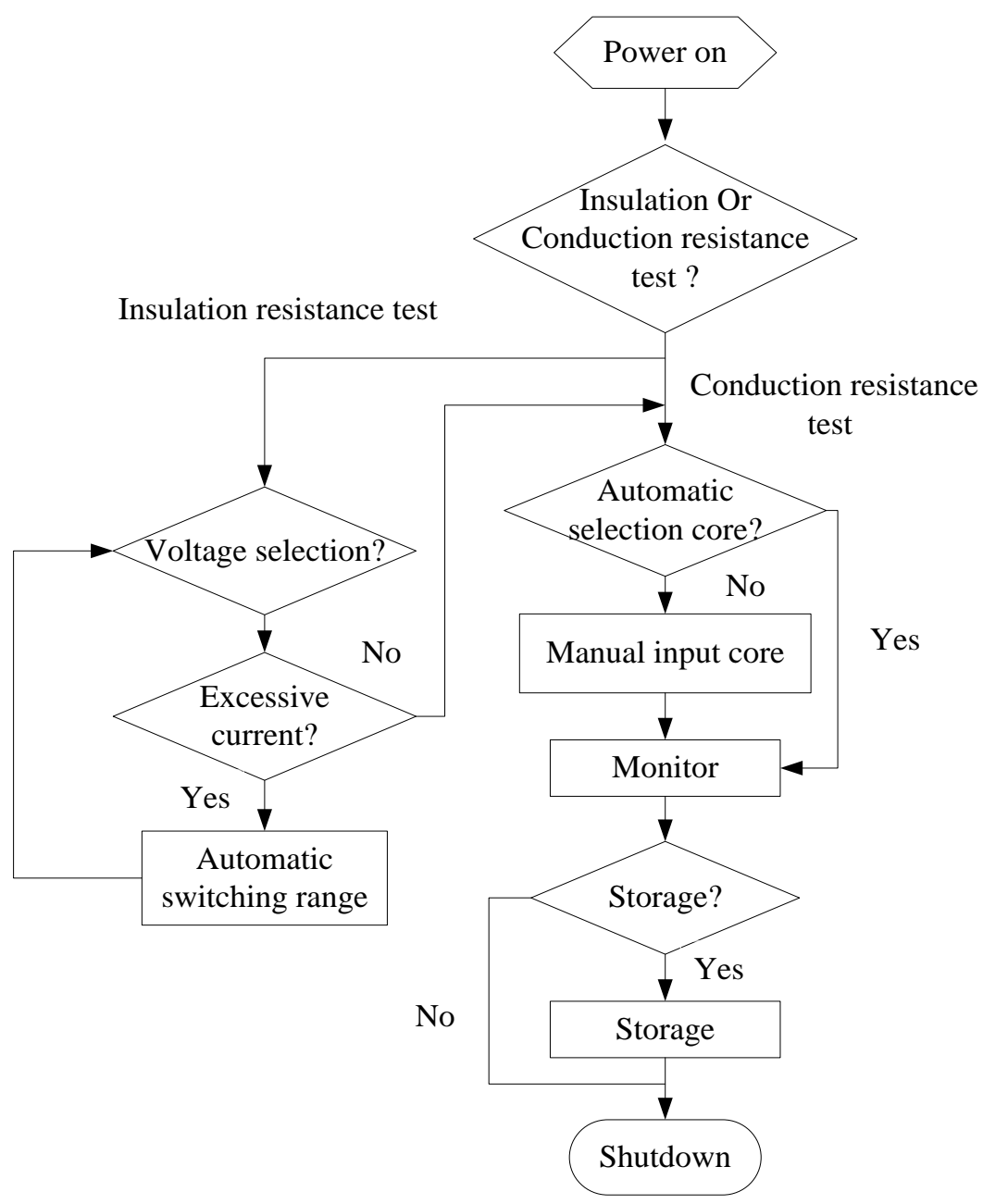

Figure 4. The testing process

\section{CONCLUSIONS}

In this paper, by using the single chip as the core, this paper designs the armored vehicle weapon system cable automatic tester, by the relay matrix, PWM high voltage switching power supply, USB communications and other advanced technology, which has high precision, speed and intelligence, overcome the shortcomings existing in the traditional test instrument to test the speed slow, prone to misuse and wrong judgment etc., this tester application will have great significance to help and improve the testing speed of cable parameters.

\section{REFERENCES}

[1] Luo Dacheng. Design of test system for missile insulation resistance, 2007, pp.126.

[2] Yang Ying. Development of the test instrument for the insulation resistance of the intelligent wire and cable, Nanjing University of Science and Technology,2007, pp.47.
[3] Zhang Zhili,Liu Pengpeng. Design of an Automatic Tester for Missile's Ground Cable, Computer Measurement \& Control,2009, pp.2012-2014.

[4] Cai Zongping, The application of single chip microcomputer in the test of missile insulation resistance, Aerospace Measurement Technology,2000, pp.51.

[5] Li Hairui,JingXiaoning,Zhang Taiping.Missile insulation test aut omation system design, Ordnance Automation,2009, pp.28-29.

[6] LiGang, DC power supply design of multi channel digital insulation resistance tester, Electrical measurement and instrumentation, 2007,pp.34.

[7] Luo Dacheng.Missile insulation test automation system design, Photoelectric control,2007, pp.126-130.

[8] Huang Qingyuan,NiuXiaochun.Automatic detection of the electrical parameters of the electronic components of the gun launched missile, Technology based research and Application,2006, pp. 100.

[9] Xu Jianguo.New type automatic monitoring system for a certain type of equipment, Ordnance Aut omation, 2009, pp.17. 